\title{
Qualidade de vida: A representação social das mulheres rurais do leste mineiro acerca de suas condições de vida
}

These Abstract

\author{
Quality of life: the social representation of rural women \\ from the east of Minas Gerais as refers to their life conditions
}

Alcione Távora Kullok.

\begin{abstract}
Resumo
Este trabalho tem como objetivo, analisar a qualidade de vida das mulheres rurais por meio de um instrumento elaborado pela Organização Mundial da Saúde (OMS), denominado WHOQOL-BREF, e a representação social que as mulheres apresentam acerca de suas condições de vida, visto serem as mulheres consideradas pelos organismos internacionais de fomento às políticas de desenvolvimento rural sustentável como agentes indispensáveis à fixação da família. Além do WHOQOL-BREF, também foram utilizados para a obtenção das informações e coleta de dados, entrevistas semiabertas, individuais, utilizando-se a gravação magnética com transcrição literal das fitas, e aplicação da técnica do Diagnóstico Participativo. Como recurso do Diagnóstico Participativo foram utilizados mapas passado, atual e futuro, relógio 24 horas, diagrama institucional e calendário anual, através da elaboração de desenhos. Nesta pesquisa pôde-se observar que o WHOQOL não foi capaz de apreender as singularidades existentes em um pequeno distrito. Embora este questionário tenha sido criado, para que houvesse indicadores subjetivos no estudo de qualidade de vida, e para que não houvesse somente dados estatísticos objetivos, suas perguntas não garantem a compreensão das respostas obtidas dentro das especificidades socioculturais da localidade analisada, o que ficou demonstrado na análise de várias facetas dos domínios do WHOQOL O Diagnóstico Rural Participativo demonstrou o quanto a dimensão da participação é fundamental para a captação das condições de vida de uma população, enquanto as pessoas não tiverem a condição de exercer o seu direito de sujeitos da sua própria vida. Também se mostrou uma experiência enriquecedora para as participantes, justamente porque teve um caráter mobilizador e com a perspectiva de construção de instrumentos de ação coletiva.
\end{abstract}

Dissertação de Mestrado 2004 Centro Universitário de Caratinga - Meio Ambiente e Sustentabilidade

\section{Disponivel para consulta em:}

http://servicos.capes.gov.br/capesdw/resumo.html?idtese=20041532077017001P8

Palavras-chave: Qualidade de Vida;

Mulheres Rurais; Condições de Vida.
Key Words: Quality of Life; Rural

Women; Life Conditions. 